\title{
Emotional Intelligence and Mood States associated with Optimal Performance
}

\author{
Andrew M. Lane (A.M.Lane2@wlv.ac.uk) \\ School of Sport, Performing Arts and Leisure, \\ University of Wolverhampton, Gorway Road, Walsall, WS13BD UK \\ Richard Thelwell (richard.thelwell@ port.ac.uk) \\ Department of Sport and Exercise Science \\ University of Portsmouth Spinnaker Building Cambridge Road Portsmouth, PO1 2ER, UK \\ Tracey J. Devonport (T.devonport@wlv.ac.uk) \\ School of Sport, Performing Arts and Leisure, \\ University of Wolverhampton, Gorway Road, Walsall, WS13BD UK
}

\begin{abstract}
This study utilized a within-subject design to investigate relationships between emotional intelligence and memories of mood states associated with optimal and dysfunctional performance in competitive sport and academic situations. Sport students $(N=436)$ completed a self-report Emotional Intelligence Scale (EIS), whilst retrospective accounts of mood states associated with optimal and dysfunctional sporting competition and academic examination performance were recorded using the Brunel Mood Scale. Repeated measures MANOVA results indicate that mood states associated with optimal and dysfunctional performance are situation-specific (Sport $\mathrm{x}$ Academic Interaction: Pillai's Trace ${ }_{8,428}=.70, p<.00$, Partial eta squared $=0.09$ ). Differences in mood states between optimal and dysfunctional performance were more pronounced for athletic situations, thereby suggesting mood states are associated with performance, but the nature of these relationships are situation-specific. A further analysis was completed to explore the role of emotional intelligence in mediating mood performance relationships. A MANCOVA comparing differences in mood states by performance (optimal and dysfunctional performance) by situation (sport and academic) controlling for EIS scores indicated a significant threeway interaction effect. Findings indicate that selfreported beliefs of emotional intelligence are associated with optimal mood states for different situations. Future research should continue to investigate the influence of emotional intelligence in performance contexts. The ultimate objective being to develop an understanding of the role emotional intelligence plays in contextualised optimal performance.
\end{abstract}

Keywords: Appraisal; emotion; stress-management; personality; psychological skills training; emotional intelligence and mood

\section{Introduction}

Anecdotal and empirical evidence indicates that individuals tend to experience intense psychological states when striving to attain highly valued goals (Lane \& Terry, 2000; Lazarus, 2001). Examples of typical emotion activating situations include sporting competition (Beedle, Terry, \& Lane, 2000; Terry, 1995), and academic examinations (Thelwell, Lane, Weston, \& Greenlees, 2007). Individuals tend to become aware of emotional states in situations where goal attainment is important (Arnold, 1960; Gross \& Thompson, 2007). When emotional states are perceived as incongruent with those required for optimal performance, this can lead to thoughts and behaviors intended to regulate them to desired levels. In this context and for the present study, optimal performance is defined as a discrete performance in which the individual achieved a highly-valued goal. Dysfunctional performance is defined as a discrete performance when the individual attempted to attain an important goal and failed to meet his/her expectation.

Given the intensity of emotions experienced during attempts to attain important performance goals in contexts such as sport (see Terry, 1995) and examinations (Thelwell, Lane, \& Weston, 2007), the ability to control emotions is clearly an important part of preparation. Research has focused on precompetition emotion, largely because an understanding of the relationship between pre-competition emotion and performance could assist practitioners develop interventions designed to help athletes obtain an emotional state that they believe will help performance. In the pre-competition phase, an athlete will activate emotional responses by thinking about an impending contest, a process that intensifies in the immediate precompetition period (Jones, 1993; Terry, 1995). Most individuals use strategies such as engaging in positive self-talk whereas some try to sleep. Others might listen to music, become talkative, or contrastingly, become 
reclusive (Stevens \& Lane, 2001; Thayer, Newman, \& McClain, 1994). In most cases, people learn strategies intended to control emotions through experience, associating success with certain emotional states experienced during performance (Hanin, 2003). Hanin $(2000,2003)$ found that athletes develop metaemotional beliefs concerning emotions linked to successful and unsuccessful performance. For example, if an athlete performed successfully whilst feeling angry, they could, upon experiencing anger in subsequent competitions, interpret anger as helpful for performance. By contrast, athletes may perceive anger as harmful for performance if previously associated with poor performance.

Although there is an absence of detailed studies examining relationships between self-perceptions of emotion regulation and emotional states experienced before and during performance, available evidence indicates meaningful associations. For example, among a sample of professional cricketers, Totterdell and Leach (2001) demonstrated that mood-regulation expectancy beliefs predicted experiencing positive mood before and during competition. It is also worth noting that both mood-regulation expectancies and mood states experienced during competition were predictors of performance. Findings demonstrating the utility of mood-expectancy beliefs have also been found in educational settings (Fer, 2004; Parker, Summerfeldt, Hogan, \& Majeski, 2004). In both studies, emotional intelligence was used to assess expectancy beliefs rather than mood-expectancy beliefs, although it is worth noting the similarity between the two constructs.

Self-report emotional intelligence is defined as 'a constellation of emotion-related self-perceptions and dispositions located at the lower levels of personality hierarchies' (Furnham \& Petrides, 2003, p.816). Furnham and Petrides described emotional intelligence as trait emotional self-efficacy, proposing that it influences perceptions of task demands, the strength of emotional responses, and subsequent behavior. It has been argued that perceptions of emotional intelligence is a central variable in the regulation of emotions (Petrides, Furnham, \& Mavroveli, 2007; Petrides, Pita, \& Kokkinaki, 2007). This contention has received recent support from a meta-analytic study indicating that self-report measures of emotional intelligence are associated with stress management and emotional control (Schutte, Malouff, Thorsteinsson, Bhullar, \& Rooke, 2007). An additional aspect of the definition of emotional intelligence proposed in the present study is also worth acknowledging. Emotional intelligence is part of a general mental ability that can be enhanced or developed over time, and as such, has the potential to offer performance improvement (Mayer, Caruso, \& Salovey, 1999; Mayer, Salovey \& Caruso, 2004; Mayer, Salovey, Caruso, \& Sitarenios, 2001).

The aim of the present study was to investigate relationships between self-report emotional intelligence and mood states associated with optimal and dysfunctional performances in two contrasting settings where goal attainment is considered important: sporting competition and an academic examination. We expected significant differences in mood by performance (optimal and dysfunctional) and by situation (sport and academic). Optimal performance should be associated with higher scores of vigor, happiness, and calmness coupled with lower scores of anger, confusion, depression, fatigue, and tension. We hypothesized that this trend would be consistent between situations, but given the physical nature of sport, optimal sport performance should be associated with significantly higher vigor and lower fatigue than optimal academic performance as these states are more representative of physiological readiness.

It was also hypothesized that self-report emotional intelligence should explain the interaction effect for differences in mood-performance relationships between competition and examination settings. Emotionally intelligent people should be more aware of emotional states experienced in different situations, and importantly, emotional states associated with optimal performance. Further, given that an aspect of emotional intelligence is the capability to regulate and utilize emotions, emotionally intelligent people should be able to use the affective component of emotions experienced in competition to help performance. Likewise, emotionally intelligent people should be sensitive to the potentially de-motivating effects of unpleasant emotions and engage in regulating strategies as part of their preparation for competition, and thereby reduce the likelihood of poor performance.

\section{Method}

\section{Participants}

Participants were 436 volunteer student athletes completing university degrees in sports related studies (Age: $M=20.94, S D=2.58 ; 213$ males, 223 females). Participants were heterogeneous in terms of previous experience and the level of competition with some athletes having competed internationally whilst others recreationally. The majority of athletes competed at club level.

Participants were recruited from each year of an undergraduate degree program. In terms of previous academic experience, all participants had secured a place at university. Although entry requirements differ between institutions, it is argued that participants demonstrated at least minimal requirements for Higher Education.

\section{Measures}

Mood Mood was measured using the 32-item Brunel Mood Scale (BRUMS: Terry, Lane, Lane, \& Keohane, 
1999; Terry, Lane \& Fogarty, 2003). The BRUMS was designed as a shortened version of the Profile of Mood States (POMS: McNair, Lorr \& Droppleman, 1971) and assesses anger, confusion, depression, fatigue, tension, and vigor. As the POMS assesses mostly unpleasant mood states, subscales of happiness and calmness from the UWIST were also included (Matthews, Jones, \& Chamberlain, 1990). Items are rated on a 5-point scale anchored by "not at all" (0) to "extremely" (4).

Lane, Soos, Leibinger, Karsai, and Hamar (2007) demonstrated evidence of factorial ability of the 32item BRUMS. In the present study, internal consistency coefficients were examined by merging mood states by situation and performance outcome into a single column. Alpha coefficients for subscales were: Anger = .77 ; calmness $=.71$; confusion $=.69 ;$ depression $=.72$; fatigue $=.73$; happiness $=.88$; tension $=.72$; and vigor $=.72$.

Emotional intelligence A 33-item measure of emotional intelligence was used. The Emotional Intelligence Scale (EIS: Schutte et al., 1998) has frequently been used to assess emotional intelligence in the general psychology literature. A common approach to using the EIS is to produce a single composite score. Recent factor analysis research has produced a sixfactor self-report measure that assesses an individual's perceptions of the extent to which s/he can appraise, regulate and utilize emotions in self and others (Lane, Thelwell, Gill, \& Weston, 2007). Thelwell, Lane, Weston, and Greenlees (2008) demonstrated that the six-factor model had utility in a sport environment.

Factors include:

1. Appraisal of own emotions; examples of items include 'I am aware of my emotions as I experience them' and 'I easily recognize my emotions as I experience them'.

2. Appraisal of others emotions; examples of items include 'I know what other people are feeling just by looking at them' and 'I can tell how people are feeling by listening to the tone of their voice'.

3. Optimism; examples of items include emotions are one of the things that make my life worth living' and 'I expect good things to happen'.

4. Regulation of emotions; examples of items include 'I have control over my emotions' and 'when I am faced with obstacles, I remember times I faced similar obstacles and overcame them'.

5. Social skills; examples of items include 'I compliment others when they have done something well' and 'I help other people feel better when they are down'.

6. Utilization of emotions; examples of items include 'when I experience a positive emotion, I know how to make it last' and 'when I am in a positive mood, solving problems is easy for me'.
Items for the EIS are rated on a 5-point Likert scale ranging from 1 (strongly agree) to 5 (strongly disagree). Alpha coefficients were: appraisal of own emotions = .71 ; appraisal of others emotions $=.73$; optimism $=.74$; regulation $=.77$; social skills $=.69$; and utilization of emotions $=.78$.

\section{Procedure}

Ethical approval was received from the institutional ethics committee of the principle author. Lecturers agreed to allow the researchers to administer questionnaires within lectures. All participants were volunteers and no incentives were offered. Participants were given a questionnaire pack containing the EIS and four different BRUMS questionnaires. The EIS asked participants to report how they generally feel and respond to different situations. Participants completed the BRUMS with reference to; a) a sports performance where they had performed well and achieved highly important goals; b) a sports performance where they had performed poorly and failed to achieve highly important goals; c) an academic written or oral examination where they had performed well and achieved highly important goals and d) an academic written or oral examination where they had performed poorly and failed to achieve highly important goals. Participants were asked to think carefully about how they felt before performance with an emphasis on moments shortly before performance started.

\section{Data analysis}

Data analysis used repeated measures multivariate analysis of variance (MANOVA) to investigate differences in mood states by performance (optimal $\mathrm{x}$ dysfunctional) and situation (sport $\mathrm{x}$ academic). A repeated measures multivariate analysis of covariance (MANCOVA) with emotional intelligence data (six sub-factors) used as covariates was used to investigate the extent to which differences in mood by performance outcome and situation were influenced by emotional intelligence. Post-hoc results were conducted on those subcomponents of emotional intelligence that demonstrated statistical significance at $p<.01$ level.

\section{Results}

Repeated measures MANOVA results for differences prior to optimal and dysfunctional performance for sport and academic performance are contained in Table 1. MANOVA revealed a significant main effect for differences in mood between optimal and dysfunctional performance in sporting settings (Sport: Pillai's Trace $8,428=.70, p<.00$, partial eta squared $=.70)$. A significant main effect was also found for differences in mood between optimal and dysfunctional performance by academic situation (Pillai's Trace ${ }_{8,428}=.66, p<.00$, partial eta squared $=.66$ ). Univariate results indicate 
Table 1: Mood \&performance between optimal and dysfunctional performance for sport and academic performance $(N=436)$

\begin{tabular}{|c|c|c|c|c|c|c|c|c|c|c|c|c|c|c|}
\hline & \multicolumn{4}{|c|}{ Sport Performance } & & & \multicolumn{4}{|c|}{ Academic Performance } & & & \multirow{2}{*}{\multicolumn{2}{|c|}{$\begin{array}{c}\text { Sport-Academic } \\
\text { Interaction }\end{array}$}} \\
\hline & \multicolumn{2}{|c|}{ Optimal } & \multicolumn{2}{|c|}{ Dysfunction } & \multirow[b]{2}{*}{$F$} & \multirow[b]{2}{*}{$E t a^{2}$} & \multicolumn{2}{|c|}{ Optimal } & \multicolumn{2}{|c|}{ Dysfunction } & \multirow[b]{2}{*}{$F$} & \multirow[b]{2}{*}{$E t a^{2}$} & & \\
\hline & $M$ & $S D$ & $M$ & $S D$ & & & $M$ & $S D$ & $M$ & $S D$ & & & $F$ & $E t a^{2}$ \\
\hline Anger & .51 & .67 & 1.32 & 1.13 & $5.23 *$ & .01 & .39 & .68 & 1.29 & 1.13 & $369.85^{*}$ & .46 & 1.94 & .00 \\
\hline Confusion & .70 & .65 & 1.35 & .96 & $315.23 *$ & .42 & .95 & .85 & 1.61 & .98 & $49.13 *$ & .10 & 1.97 & .00 \\
\hline Calmness & 1.61 & .90 & 1.01 & .79 & $270.00 *$ & .38 & 1.44 & .94 & .87 & .75 & $27.46^{*}$ & .06 & $3.33 *$ & .01 \\
\hline Fatigue & .54 & .69 & 1.25 & .99 & $34.26^{*}$ & .07 & .81 & .88 & 1.40 & 1.03 & $246.69^{*}$ & .36 & $4.87 *$ & $.01^{*}$ \\
\hline Happiness & 2.29 & .85 & 1.14 & .87 & $105.45^{*}$ & .20 & 1.86 & .95 & .87 & .80 & $592.37 *$ & .58 & $7.88^{*}$ & .02 \\
\hline Tension & 1.31 & .81 & 1.68 & 1.04 & $15.98 *$ & .04 & 1.43 & .97 & 1.87 & 1.01 & $116.31^{*}$ & .21 & 1.67 & .00 \\
\hline Vigor & 3.06 & .74 & 1.83 & .96 & $301.91 *$ & .41 & 2.37 & .89 & 1.34 & .88 & $735.90 *$ & .63 & $13.57 *$ & $.03 *$ \\
\hline
\end{tabular}

that higher levels of vigor, calmness, and happiness coupled with lower anger, confusion, depression, fatigue and tension scores were associated with optimal performance for both academic and sport performance.

MANOVA revealed a significant sport and academic performance interaction effect (Sport $x$ Academic scores for vigor, calmness and happiness coupled with lower fatigue. Dysfunctional sport performance was associated with higher depression.

With differences in mood by performance outcome and situation demonstrated, emphasis moved to the extent to which emotional intelligence could explain this effect.

MANCOVA revealed significant main effects for three emotional intelligence subcomponents: appraisal of own emotions (Wilks' lambda $8,421=.96, p=.01$, partial eta squared $=.04$ ), optimism (Wilks' lambda 8,421 $=.96, p=.04$, partial eta squared $=.04)$, and utilization of emotions (Wilks' lambda ${ }_{8,421}=.95, p=.01$, partial eta squared $=.05)$. Post-hoc results indicated that appraisal of own emotions was associated with low scores of anger $(F(1,428)=4.12, p=.04$, partial eta squared $=.01)$, optimism was associated with high scores of vigor $(F(1,428)=6.79, p=.01$, partial eta squared $=.02)$, and utilization of emotions was associated with low tension scores $(F(1,428)=7.46, p=$ .00 , partial eta squared $=.02$ ).

MANCOVA comparing differences in mood states by performance (optimal and dysfunctional performance) and situation (sport and academic) by EIS scores indicated significant interaction effects for three emotional intelligence subcomponents: appraisal of others emotions (Wilks' lambda ${ }_{8,421}=.96, p=.02$, partial eta squared $=.04$ ), social skills (Wilks' lambda $8,421=.96, p=.04$, partial eta squared $=.04$ ) and utilization of emotions (Wilks' lambda ${ }_{8,421}=.95, p=$ .01 , partial eta squared $=.05$ ).

Post-hoc follow-up tests on significant emotional intelligence subscales indicated appraisal of other's emotion was associated with lower fatigue scores
Interaction: Pillai's Trace ${ }_{8,428}=.70, p<.00$, partial eta squared $=.09)$. Interaction results indicate that the difference between optimal and dysfunctional performance was much higher for calmness, depression, fatigue, happiness, and vigor in sport. Optimal sport performance was associated with significantly higher $(F(1,428)=16.64, p<.00$, partial eta squared $=.04)$. Social skills was associated with lower scores of confusion $(F(1,428)=15.00, p=.00$, partial eta squared $=.03)$ and higher calmness $(F(1,428)=8.33, p$ $=00$, partial eta squared $=.02)$. Utilization of emotions was associated with higher scores of happiness $(F(1,428)=5.01, p=.03$, partial eta squared $=.01)$ and lower scores of confusion $(F(1,428)=4.30, p=.04$, partial eta squared $=.01$ ).

\section{Discussion}

This study investigated relationships between emotional intelligence and mood states associated with optimal performance in sport and academic settings. Findings show that retrospective assessments of mood differ between optimal and dysfunctional performance, and that these relationships are situation-specific. In the present study, mood states associated with physical readiness such as vigor, characterized by feeling energetic and alert, and fatigue, characterized by feeling tired and exhausted, may be a primary influence in athletic tasks due to the influence of physical factors on performance.

Emotional intelligence is argued to be a central variable in the regulation of emotions (Petrides et al., 2007; Petrides et al., 2007). The present study investigated the mediating influence of trait emotional intelligence in two potentially emotion-stimulating situations; academic and sport performance. Emotionally intelligent individuals should be aware of emotions experienced in different situations, and the influence of emotions on behavior. Being able to anticipate the possible effects of emotions enables 
individuals to engage regulatory behavior intended to adjust emotions to optimal levels.

Findings show that emotional intelligence scores were associated with differences in mood states and optimal and dysfunctional performance. For example, utilization of emotions was associated with differences in happiness and confusion in sport competition and exam situations. It is plausible that highly emotionally intelligent individuals are aware of the influence of happiness and confusion in mediating the impact of other emotions on performance. As depression has an undesirable impact on performance in academic contexts, emotionally intelligent individuals take action to reduce feelings of depression, and sustain a sense of happiness.

Results of the present study offer some support for the contention of Fer (2004) who suggests that students with high emotional intelligence achieve their academic potential as they are able to handle emotions more effectively (Parker et al., 2004). Results also offer support for the notion that trait or self-reported emotional intelligence can facilitate sporting performance (Zizzi, Deaner, \& Hirschhorn, 2003). Individuals may seek to use the affective content of emotions to motivate themselves in competition (Hanin, 2003).

Gohm (2003) investigated the role of individual differences in emotion regulation reporting that $30 \%$ of individuals experienced their emotions intensely but were unclear of their meaning (overwhelmed individuals). These participants exhibited different mood patterns to participants clear of meaning. Overwhelmed individuals may be more motivated than others to attenuate their mood states, but may be unable or unwilling to avail themselves of important affective information. Consequently, they may attenuate moods inappropriately. This is a significant finding given that the affective content of emotions may influence motivation to work toward important goals and that such individuals could possibly miss important information required for goal attainment. From a research perspective, it is likely that the present sample contained such individuals, and their presence is likely to have dampened the strength of findings. From an applied perspective, evidence supporting the presence of overwhelmed individuals lends support to advocates who propose that emotional intelligence can be enhanced through guided training.

It should be noted that a limitation of this study relates to the assessment of mood using a retrospective approach. Lane and Terry (2000) were heavily critical of studies assessing mood that use a retrospective approach. They argue that retrospective measures should not be treated as measures of mood taken in real time. The present study supports this notion, however, it is argued that retrospective mood data provides useful information regarding the development of metaemotional beliefs (Hanin, 2003). Recall that these are beliefs concerning emotions linked to successful and unsuccessful performance. Such beliefs possessed by an individual are highly meaningful whether accurate or not. Baumeister, Vohs, DeWall, and Zhang (2007) argue that memories of emotional states provide a powerful source of information in the generation of future emotions, and cognitions surrounding these emotions. Baumeister et al. proposed that the influence of emotion on performance is indirect in that individuals engage in behaviors intended to pursue or avoid anticipated emotional outcomes.

A second limitation refers to the highly-subjective nature of optimal and dysfunctional performance. Numerous factors will influence this process including the recency of the performance and memory capability. A third limitation relates to the extent to which an undergraduate student-athlete population generalizes to a wider audience. It is possible that within the undergraduate sample, the course studied and the level of students could be influential. Equally, the present study did not control for the type of sport. Future research could explore individual or team comparative analysis between optimal and dysfunctional performance in both the academic and sporting situations.

\section{Conclusions}

The results of the present study indicate that retrospective mood measures demonstrated strong relationships with academic and sport performance. Future research is required to investigate the nature and influence of emotional intelligence on emotional states experienced during performance, and the resultant quality of performance.

\section{References}

Arnold, M. B. (1960). Emotion and personality (1: Psychological aspects). New York: Columbia University Press.

Baumeister, R. F., Vohs, K., DeWall, C. N. \& Zhang, L. (2007). How emotion shapes behavior: Feedback, anticipation and reflection, rather than direct causation. Personality and Social Psychology Review, 11, 167-203.

Beedie, C. J., Terry, P. C., \& Lane, A. M. (2000). The Profile of Mood States and athletic performance: Two meta-analyses. Journal of Applied Sport Psychology, 12, 49-68.

Fer, S. (2004). Qualitative evaluation of emotional intelligence in-service program for secondary school teachers. The Qualitative Report, 9, 562-588.

Furnham, A., \& Petrides, K. V. (2003) Trait emotional intelligence and happiness. Social Behavior and Personality, 31, 815-824.

Gohm, C. L. (2003). Mood Regulation and Emotional Intelligence: Individual Differences. Journal of Personality and Social Psychology, 84, 594-607. 
Hanin, Y. (2000). Successful and poor performance and emotions. In Y. Hanin (Ed.), Emotions in sport (pp. 157-189). Champaign, IL: Human Kinetics.

Hanin, Y. L. (2003, February). Performance Related Emotional States in Sport: A Qualitative Analysis [48 paragraphs]. Forum Qualitative Sozialforschung / Forum: Qualitative Social Research [On-line Journal], 4 (1). See at: http://www.qualitativeresearch.net/fqs-texte/1-03/1-03hanin-e.htm

Jones, M. (2003). Controlling emotions in sport. The Sport Psychologist, 17, 471-486.

Lane, A. M. (2007). The rise and fall of the iceberg: development of a conceptual model of moodperformance relationships. A.M. Lane (ed.), Mood and human performance: Conceptual, measurement, and applied issues (pp1-34). Hauppauge, NY: Nova Science.

Lane, A. M., \& Terry, P. C. (2000). The nature of mood: Development of a conceptual model with a focus on depression. Journal of Applied Sport Psychology, 12, 16-33.

Lane, A. M., Soos, I., Leibinger, E., Karsai, I., \& Hamar, P. (2007). Validity of the Brunel Mood Scale for use with UK, Italian and Hungarian Athletes. In A. M. Lane (ed.), Mood and human performance: Conceptual, measurement, and applied issues (pp119130). Hauppauge, NY: Nova Science.

Lane, A. M., Thelwell, R., Gill, G., \& Weston, N. (2007). Confirmatory factor analysis of the Emotional Intelligence Scale on an athletic sample. Journal of Sports Sciences, 25, 312.

Lazarus, R. S. (2001). Stress and Emotion: A new synthesis. Human Relations, 54, 792-803.

Matthews, G., Jones, D. M., \& Chamberlain, A. G. (1990). Refining the measurement of mood: The UWIST Mood Adjective Checklist. British Journal of Psychology, 81, 17-42.

Mayer, J., Caruso, D., \& Salovey, P. (1999). Emotional intelligence meets traditional standards for an intelligence. Intelligence, 27, 267-298.

Mayer, J. D., Salovey, P., \& Caruso, D. R. (2004). Emotional intelligence: Theory, findings, and implications. Psychological Inquiry, 15, 197-215.

Mayer, J. D., Salovey, P., Caruso, D. R., \& Sitarenios, G. (2001). Emotional intelligence as a standard intelligence. Emotion, 1, 232-242.

McNair, D. M., Lorr, M., \& Droppleman, L. F. (1971). Manual for the Profile of Mood States. San Diego, CA: Educational and Industrial Testing Services.

Parker, J. D. A., Summerfeldt, L. J., Hogan, M. J., \& Majeski, S. A. (2004). Emotional intelligence and academic success: examining the transition from high school to university. Personality and Individual Differences, 36, 163-172.

Petrides, K. V., Furnham, A., \& Mavroveli, S. (2007). Trait emotional intelligence: Moving forward in the field of EI. In G. Matthews, M. Zeidner \& R. Roberts, R. (Eds.). Emotional intelligence: Knowns and unknowns (Series in Affective Science). Oxford: Oxford University Press.

Petrides, K. V., Pita, R., \& Kokkinaki, F. (2007). The location of trait emotional intelligence in personality factor space. British Journal of Psychology, 98, 273289.

Salovey, P., \& Mayer, J. D. (1990). Emotional intelligence. Imagination, Cognition \& Personality, 9, 185-211.

Schutte, N. S., Malouff, J. M., Hall, L. E., Haggerty, D. J., Cooper, J. T., Golden, C. J., \& Dornheim, L. (1998). Development and validation of a measure of emotional intelligence. Personality and Individual Differences, 25, 167-177.

Schutte, N. S., Malouff, J. M., Thorsteinsson, E. B., Bhullar, N., \& Rooke, S. E. (2007). A meta-analytic investigation of the relationship between emotional intelligence and health. Personality and Individual Differences, 42, 921-933.

Stevens, M. J., \& Lane, A. M. (2001). Mood-regulating strategies used by athletes. Athletic Insight. http://www.athleticinsight.com/Vol3Iss3/MoodRegul ation.htm

Terry, P. C. (1995). The efficacy of mood state profiling among elite competitors: A review and synthesis. The Sport Psychologist, 9, 245-260.

Terry, P. C., Lane, A. M., \& Fogarty, G. (2003). Construct validity of the Profile of Mood States-A for use with adults. Psychology of Sport and Exercise, 4, 125-139.

Terry, P. C., Lane, A. M., Lane, H. J., \& Keohane, L. (1999). Development and validation of a mood measure for adolescents: POMS-A. Journal of Sports Sciences, 17, 861-872.

Thayer, R. E., Newman, R., \& McClain, T. M. (1994). Self-regulation of mood: Strategies for changing a bad mood, raising energy, and reducing tension. Journal of Personality and Social Psychology, 67, 910-925.

Thelwell, R. C., Lane, A. M., \& Weston, N. J. V. (2007). Mood states, self-set goals, self-efficacy and performance in academic examinations. Personality and Individual Differences, 42, 673-583.

Thelwell, R., Lane, A. M., Weston, N. J. V., \& Greenlees, I. A. (2008). Examining relationships between emotional intelligence and coaching efficacy. International Journal of Sport and Exercise Psychology, 6, 224-235

Totterdell, P., \& Leach, D. (2001). Negative mood regulation expectancies and sports performance: an investigation involving professional cricketers. Psychology of Sport and Exercise, 2, 249-265.

Zizzi, S. J., Deaner, H. R., \& Hirschhorn, D. K. (2003). The relationship between emotional intelligence and performance among college baseball players. Journal of Applied Sport Psychology, 15, 262-269. 
Correspondence to: Prof. Andrew Lane, School of Sport, Performing Arts and Leisure, University of Wolverhampton, Gorway Road, Walsall, WS1 3BD, United Kingdom.

A.M.Lane2@wlv.ac.uk

\section{Research Profile}

Andrew Lane is a Professor of Sport Psychology at the University of Wolverhampton. He is accredited from the British Association of Sport and Exercise Sciences (BASES) for scientific support and research, and is a Chartered Psychologist with the British Psychological Society. He has authored more than 100 peer refereed journal articles and edited two books. He is the editor of The Sport and Exercise Scientist, and sits on the editorial board of the Journal of Sports Science and Medicine and Journal of Hospitality, Sport, Tourism, Education, and advisory boards for the Journal of Sports Sciences and Medicine and Science in Sport and Exercise. He has organized two national conferences, including the annual BASES conference. His applied work has involved a number of clients including the English Institute of Sport and the London Boxing Association where he was involved in preparations of boxers for World Championship contests. A former amateur boxer, he remains active in sport as a runner and duathlete and after shedding 20 kilos is enjoying competition again.

Richard Thelwell is a Principal Lecturer in Sport Psychology at the University of Portsmouth. He is accredited from the British Association of Sport and Exercise Sciences (BASES) for scientific support and research, and is a Chartered Psychologist with the British Psychological Society. He has authored more than 30 peer refereed journal articles and has contributed chapters to two edited books. Richard is also on the editorial boards for The Sport and Exercise Scientist and International Review of Sport and Exercise Psychology. In addition to his research Richard is an experienced practitioner who has worked within professional soccer and currently works with a professional cricket club and for the Royal Yachting Association. Further to this, Richard has delivered several applied workshops for BASES and he also sits on the Accreditation and Fellowship Committee as the Psychology representative. A former county cricketer, he remains active in sport as a league cricketer.

Tracey Devonport is chartered by the British Psychological Society and accredited by the British Association of Sport and Exercise Science (BASES) for support. Her research interests focus on applied sport psychology and coping strategies employed by individuals to bring about goal attainment. She has 15 peer refereed academic papers and given over 50 presentations at academic conferences. She has delivered professional development courses on emotional intelligence for BASES. Her applied work has included a number of clients including England Netball (players and officials) and England Volleyball. She currently partakes in sprint triathlons in order to maintain an active lifestyle. 